\title{
Biofilm released cells can easily be obtained in a fed-batch system using ica+ but not with ica- isolates
}

\author{
Vânia Gaio ${ }^{1}$, Nuno Cerca ${ }^{\text {Corresp. } 1}$ \\ ${ }^{1}$ Centre of Biological Engineering (CEB), Laboratory of Research in Biofilms Rosário Oliveira (LIBRO), University of Minho, Braga, Portugal \\ Corresponding Author: Nuno Cerca \\ Email address: nunocerca@ceb.uminho.pt
}

Staphylococcus epidermidis is one of the major opportunistic bacterial pathogens in healthcare facilities, mainly due to its strong ability to form biofilms in the surface of indwelling medical devices. To study biofilms under in vitro conditions, both fed-batch and flow systems are widely used, with the first being the most frequent due to their low cost and ease of use.

Aim. To assess if a fed-batch system previously developed to obtain biofilm released cells (Brc) from strong biofilm producing $S$. epidermidis isolates could also be used to obtain and characterize Brc from isolates with lower abilities to form biofilms.

Methodology. The applicability of a fed-batch system to obtain Brc from biofilms of 3 ica $^{+}$and 3 ica $^{-}$ isolates was assessed by quantifying the biofilm and Brc biomass by optical density (OD) and colonyforming units (CFU) measurements. The effect of media replacement procedures of fed-batch systems on the amount of biofilm was determined by quantifying the biofilm and biofilm bulk fluid, by CFU, after consecutive washing steps.

Results. The fed-batch model was appropriate to obtain Brc from ica ${ }^{+}$isolates, that presented a greater ability to form biofilms and release cells. However, the same was not true for ica isolates, mainly because the washing procedure would physically remove a significant number of cells from the biofilm.

Conclusions. This study demonstrates that a fed-batch system is only feasible to be used to obtain Brc from $S$. epidermidis when studying strong and cohesive biofilm-forming isolates. 
1 Biofilm released cells can easily be obtained in a fed-

2 batch system using ica+ but not with ica- isolates

3

4 Vânia Gaio ${ }^{1}$, Nuno Cerca ${ }^{1}$

5

$6{ }^{1}$ Centre of Biological Engineering (CEB), Laboratory of Research in Biofilms Rosário Oliveira

7 (LIBRO), University of Minho, Braga, Portugal

8

9 Corresponding Author:

10 Nuno Cerca ${ }^{1}$

11 Centre of Biological Engineering - University of Minho, Campus de Gualtar, 4710-057 Braga,

12 Portugal.

13 Email address: nunocerca@ceb.uminho.pt

14

15

16

17

18

19

20

21

22

23

24

25

26

27

28

Peer] reviewing PDF | (2020:04:48028:1:1:CHECK 5 Jun 2020) 


\section{Abstract}

30 Staphylococcus epidermidis is one of the major opportunistic bacterial pathogens in healthcare

31 facilities, mainly due to its strong ability to form biofilms in the surface of indwelling medical

32 devices. To study biofilms under in vitro conditions, both fed-batch and flow systems are widely

33 used, with the first being the most frequent due to their low cost and ease of use.

34 Aim. To assess if a fed-batch system previously developed to obtain biofilm released cells (Brc)

35 from strong biofilm producing $S$. epidermidis isolates could also be used to obtain and

36 characterize Brc from isolates with lower abilities to form biofilms.

37 Methodology. The applicability of a fed-batch system to obtain Brc from biofilms of $3 \mathrm{ica}^{+}$and $383 \mathrm{ica}^{-}$isolates was assessed by quantifying the biofilm and Brc biomass by optical density (OD) 39 and colony-forming units (CFU) measurements. The effect of media replacement procedures of 40 fed-batch systems on the amount of biofilm was determined by quantifying the biofilm and 41 biofilm bulk fluid, by CFU, after consecutive washing steps.

42 Results. The fed-batch model was appropriate to obtain Brc from $\mathrm{ica}^{+}$isolates, that presented a 43 greater ability to form biofilms and release cells. However, the same was not true for $\mathrm{ica}^{-}$ 44 isolates, mainly because the washing procedure would physically remove a significant number of 45 cells from the biofilm.

46 Conclusions. This study demonstrates that a fed-batch system is only feasible to be used to 47 obtain Brc from $S$. epidermidis when studying strong and cohesive biofilm-forming isolates. 48 50 51

Keywords. Fed-batch systems; Biofilm-released cells; Biofilm disassembly; S. epidermidis

(1)

5

54

5




\section{Introduction}

64

65 Staphylococcus epidermidis is a well-known nosocomial pathogenic associated with recurrent

66 biofilm-infections, acknowledged as the major agent involved in biofilm-associated medical

67 devices infections (Becker et al., 2014). Importantly, this bacterium, which was previously seen

68 as a commensal microorganism due to its benign relationship with the host (Cogen et al., 2008;

69 Gardiner et al., 2017), is nowadays accepted as an important opportunistic pathogen, of

70 particular concern in ill and immunocompromised patients (Otto, 2009). S. epidermidis

71 infections are more likely to happen upon invasive procedures involving indwelling medical

72 devices, in which the physiological barriers are compromised, since this bacterium is a

73 ubiquitous inhabitant of the skin and mucosae in humans (Ziebuhr et al., 2006) and has a strong

74 ability to form biofilms on the surface of medical devices (Cerca et al., 2005; Laverty et al.,

75 2013). Bacteria within biofilms are undoubtedly more resistant to antibiotics (Albano et al.,

76 2019; Cerca et al., 2005a; Dias et al., 2018) and to the host immune defense (Cerca et al., 2006;

77 Gray et al., 1984; Yao et al., 2005), contributing to the persistence and recurrence of infections

78 (Mah, 2012; Schommer et al., 2011; Singh and Ray, 2014). For all these reasons, biofilms have

79 been a major research target and extensive studies allowed to characterize the biofilm lifecycle

80 and divide it into three main stages: attachment, maturation and disassembly (as reviewed in

81 (Boles and Horswill, 2011; Otto, 2013)). The importance of a better characterization of the

82 disassembly process in biofilms has been pointed out, since cells released from the biofilm can

83 enter the systemic circulation and contribute to the spreading of the infection (Boles and

84 Horswill, 2011; Kaplan, 2010) and cause severe systemic diseases, as bacteraemia (Cervera et

85 al., 2009; Wang et al., 2011) which are associated with high levels of morbidity and mortality

86 among immunocompromised patients (Kleinschmidt et al., 2015; Rogers et al., 2009).

87 Both fed-batch and dynamic systems have been used to study and characterize initial adhesion

88 (Cerca et al., 2005b; Isberg and Barnes, 2002) and maturation of the biofilm (Moormeier and

89 Bayles, 2014; Periasamy et al., 2012). However, both present advantages and drawbacks,

90 depending on the main focus of the study (Bahamondez-Canas et al., 2019). The few studies

91 addressing disassembly rely almost entirely on dynamic systems, which is not surprising, as

92 these systems present key advantages such as a controlled flow, allowing a continuous diffusion

93 of oxygen, nutrients and waste, and are thought to be a more accurate representation of the

Peer) reviewing PDF | (2020:04:48028:1:1:CHECK 5 Jun 2020) 
94 conditions in which biofilms are formed in various diseases, as previously reviewed (Azeredo et 95 al., 2017; Bahamondez-Canas et al., 2019). However, these systems are significantly more expensive and are often more difficult to assemble, being essential to have good background knowledge on hydrodynamics to study biofilms in such conditions (Yawata et al., 2016). Hence, it is no wonder that fed-batch systems are more frequently used on biofilm research, since they are easier to implement and already widely used under in vitro conditions (Azeredo et al., 2017; Bahamondez-Canas et al., 2019). Thus, the ability to implement fed-batch systems to highthroughput research in biofilms disassembly would be beneficial, as it would allow more studies to be undertaken on this research topic.

Earlier, we demonstrated the feasibility to use a fed-batch system to obtain S. epidermidis cells released from biofilms (Brc) (França et al., 2016a; Gaio and Cerca, 2019). However, we failed to include low biofilm-forming isolates on those studies and, as a consequence, the applicability of this model on such isolates could be questioned. Hence, the aim of the current study was to better understand the limitations of a fed-batch system to obtain Brc from S. epidermidis biofilms, by testing its potential to characterize Brc from $\mathrm{ica}^{+}$and $\mathrm{ica}^{-}$isolates with distinct abilities to form biofilms.

\section{Materials \& Methods}

\section{Bacterial isolates and growth conditions}

Six isolates of $S$. epidermidis, with different abilities to form biofilms and characterized by the presence $(+)$ or absence (-) of the intercellular adhesion gene (ica), generally involved in $S$. epidermidis biofilm formation (Cafiso et al., 2004) were selected to conduct this study (Table 1). Growth conditions followed the fed-batch model previously described to obtain Brc from $S$. epidermidis (França et al., 2016a). First, a colony of S. epidermidis was inoculated into $2 \mathrm{~mL}$ of Tryptic Soy Broth (TSB) (Liofilchem, Teramo, Italy) and incubated overnight at $37^{\circ} \mathrm{C}$ with shaking at $120 \mathrm{rpm}$ in an orbital shaker. The overnight inoculum was then diluted in the same growth medium to reach an optical density (OD) of $0.250 \pm 0.05$, measured at $640 \mathrm{~nm}$, which corresponds to a concentration of approximately $2 \times 10^{8} \mathrm{CFU} / \mathrm{mL}$ (Freitas et al., 2014). To form biofilms, $15 \mu \mathrm{L}$ of the previously adjusted suspension were added to $1 \mathrm{~mL}$ of TSB supplemented with $0.4 \%(\mathrm{v} / \mathrm{v})$ glucose (TSBG) to induce biofilm formation, into a 24-well microtiter plate (Orange Scientific, Braine-1'Alleud, Belgium), that was incubated in an orbital incubator at $37^{\circ} \mathrm{C}$ 
125 with agitation at $120 \mathrm{rpm}$, for as long as $72( \pm 1)$ hours. Spent medium was carefully removed 126 after each $24( \pm 1)$ hours of incubation, followed by washing twice the biofilm with a $0.9 \%(\mathrm{~m} / \mathrm{v})$

$127 \mathrm{NaCl}$ solution to remove unattached cells. Next, $1 \mathrm{~mL}$ of fresh TSBG was carefully added to the 128 biofilms and the plate was incubated in the same temperature and agitation conditions. Then, at 129 either 28, 48 or 72-hours of growth, the supernatant was removed and biofilms were washed 130 twice with saline solution. Remaining biofilms cells were scraped from the microtiter plate with 131 the aid of a plastic tip and resuspended in $1 \mathrm{~mL}$ of the $\mathrm{NaCl}$ solution. Cells were pooled together 132 from at least 4 distinct disrupted biofilms to decrease biofilm formation variability (Sousa et al., 133 2014). Planktonic cultures were grown in an orbital shaker for $24( \pm 1)$ hours at $37^{\circ} \mathrm{C}$ with 134 shaking at $120 \mathrm{rpm}$. Finally, Brc were carefully aspirated from the biofilm bulk fluid after 28, 48 135 and 72 hours of growth. A schematic representation of the method used to culture and collect the populations mentioned in this section was included in Supplementary Data S1.

137

\section{Homogenization and quantification of the populations}

Before quantification, all 3 populations (disrupted biofilm cells, Brc and planktonic cells) were homogenized by sonication through a pulse of 5 seconds at $40 \%$ amplitude (Ultrasonic Processor Model CP-750, Cole-Parmer, Illinois, U.S.A.). As shown before, this sonication cycle did not affect cell viability (Cerca et al., 2005a). The total biomass of all bacterial populations was quantified by OD measurement at $640 \mathrm{~nm}\left(\mathrm{OD}_{640}\right)$, as previously optimized (Freitas et al., 2014). At least three independent experiments, with technical duplicates, were performed.

\section{Effect of consecutive biofilm washing on cell detachment from the biofilms}

147 Biofilms were formed for 24 hours, as described above. Then, the supernatant was carefully 148 removed and the total number of cells on the supernatant was quantified by CFU. Biofilms were 149 then washed with a saline solution, up to 6 consecutive times. Between each wash, bacteria in the supernatant were quantified by CFU. Simultaneously, the quantification of CFU of the remaining biofilm was done after 1, 2 and 6 washes. Four independent assays were performed for each

152 strain and technical duplicates were used.

153

\section{Quantification of active dispersion of cells from $24 \mathrm{~h}$ biofilms}


155 After discarding the spent medium and washing twice the preformed 24 hours biofilms, $1 \mathrm{~mL}$ of

156 TSB was carefully added to the wells. In half of the biofilm wells, the newly added TSB was

157 immediately transferred into empty sterile wells, as described in Figure 1. This medium

158 contained cells released from the pre-established biofilm $(\mathrm{Brc})$, due to the shear forces exerted by

159 medium addition, as determined before (França et al., 2016a). The plates were incubated at $37^{\circ} \mathrm{C}$

160 with shaking at $120 \mathrm{rpm}$. At different time points, a $20 \mu \mathrm{L}$ aliquot was collected from both

161 conditions. The number of cultivable cells was determined by CFU. Four independent

162 experiments with three technical replicates were performed.

163

\section{Comparison of the antibiotic susceptibility of Brc collected at distinct time points}

165 Brc were collected after $28 \mathrm{~h}, 48 \mathrm{~h}$ and $72 \mathrm{~h}$ of biofilm formation. The $28 \mathrm{~h}$ time point was included

166

to assess the effect of Brc physiology $4 \mathrm{~h}$ after the first medium removal. The bacterial cell

167

168

169

170

171

172

173

174

175

176

177

178

179

180

181

182

183

184

185

concentration was adjusted by OD to a final concentration of around $2 \times 10^{8} \mathrm{CFU} / \mathrm{mL}$ and bacterial suspensions were incubated with peak serum concentrations (PSC) of vancomycin (40 $\mathrm{mg} / \mathrm{L})$, rifampicin $(10 \mathrm{mg} / \mathrm{L})$ or tetracycline $(16 \mathrm{mg} / \mathrm{L})$ (National Committee for Clinical Laboratory Standards, 1997) for 2 hours at $37^{\circ} \mathrm{C}$ with agitation at $120 \mathrm{rpm}$. Controls were performed in simultaneous by incubating the suspensions in the same conditions, without the addition of the antibiotics. The effect of the antibiotics was assessed by CFU counting upon 10fold serial dilutions and plating into Tryptic Soy Agar (TSA) plates. This assay was performed with technical duplicates and at least three independent times.

\section{Statistical analysis}

Statistical significance between consecutive washes performed on biofilms (Figure 2) and between control and antibiotic-treated samples (Supplementary Data S2) was determined with one-way ANOVA multiple comparisons $(p<0.05)$. Statistical difference regarding growth kinetics in the presence or absence of the originating biofilm (Figure 3) was determined using multiple T-tests $(p<0.01)$. All analysis was performed using GraphPad Prism version 6 (Trial version, CA, USA). At least three replicates (independent experiments) were performed for all assays.

\section{Results}


186

187

188

189

190

191

192

193

194

195

196

197

198

199

200

201

202

203

204

205

206

207

208

209

210

211

212

213

215

214 A higher number of cells is released to the supernatant when growing in the presence of

Characterization of biofilm formation and Brc collection by multiple $S$. epidermidis isolates A total of 6 distinct $S$. epidermidis isolates, previously characterized regarding their biofilm formation ability and the presence of biofilm-associated genes, namely the ica operon, were selected for this study (Cerca et al., 2013; Freitas et al., 2017). Initially, biofilms were grown up to $72 \mathrm{~h}$. The ability to produce Brc over time, using the implemented fed-batch system, was evaluated by calculating the ratio between the number of cells existing in the biofilm bulk fluid and within the biofilm biomass (Bbf/B) (Table 2). From the 6 isolates used in this study, all $3 \mathrm{ica}^{+}$ isolates produced remarkably more biofilm than isolates without the ica gene, especially after $72 \mathrm{~h}$ of incubation. This was not surprising since several studies showed a relation between the presence of the ica locus and the increased ability to form biofilms (Heilmann et al., 1996; Mack et al., 1994; Qin et al., 2007a), despite also being known that some ica- isolates are also able to produce biofilms (Dice et al., 2009; O’Gara, 2007; Qin et al., 2007b; Tormo, 2005). Interestingly, it was observed that the thickest biofilms produced had a lower Bbf/B ratio.

Washing biofilm and replacing the growth medium in fed-batch systems triggers the physical detachment of biofilm cells

It was previously shown that the typical medium replacement procedures needed for fed-batch systems trigger the detachment of cells from the biofilm due to shear forces (França et al., 2016a). Using the selected isolates, a total of 6 consecutive washing steps were performed on each biofilm, followed by quantification of the number of cells released immediately after each wash, as well as cells remaining in the biofilm (Figure 2). Interestingly, all strains used each successive wash kept detaching cells from the biofilm, ranging from $\sim 10^{7}$ to $\sim 10^{6} \mathrm{CFU} / \mathrm{mL}$ per wash, independently of their biofilm formation capacity. Remarkably, the total biomass of stronger biofilms producers (9142, DEN69 and PT13032) was only moderately affected after the 6 washes, with circa 40\% decrease of total biofilm biomass from the first to the last washing step. Conversely, ica- isolates (ICE102, DEN185 and PT12004) biofilm structure was relatively more affected by shear forces, with more than $70 \%$ of the biofilm being removed after the 6 washes $(p=0.03)$. strong biofilms

Peer) reviewing PDF | (2020:04:48028:1:1:CHECK 5 Jun 2020) 
216 To differentiate between physical detachment and active dispersion of cells, a second experiment 217 was performed. After washing a preformed $24 \mathrm{~h}$ biofilm and replacing the growth medium, the 218 total number of cells in the bulk fluid was quantified right after medium replacement and after $2 \mathrm{~h}$ 219 of incubation. In half of the wells, the bulk fluid containing Brc was transferred to new sterile 220 wells. As shown before for strain 9142 (França et al., 2016a), the presence of the originating 221 biofilm significantly increased the number of cells in the bulk fluid of $i c a^{+}$strains, especially at 222120 minutes (Figure 3), when compared to the inoculum transferred to new sterile wells (in the 223 absence of the preformed biofilm). Conversely, the same was not true for the $i c a^{-}$isolates, since 224 the effect of growth in the presence of the biofilm was significantly less pronounced and no 225 statistical differences between growing in the presence or absence of the originating biofilm were 226 found, growing up to 120 minutes. This is not surprising since we know from the previous 227 experiment that a significant number of cells was removed from the weakest biofilms, leaving a 228 low amount of cells available to be released.

229

Brc obtained at different time points present the same antimicrobial susceptibility to vancomycin, tetracycline and rifampicin

232 Previously, we observed that Brc collected from 24h preformed biofilm, up to $4 \mathrm{~h}$ after medium 233 replacement, presented enhanced tolerance to vancomycin, tetracycline and rifampicin (França et 234 al., 2016a). As a complementary analysis to be included in this study, we decided to test if this 235 enhanced antimicrobial tolerance was somewhat influenced if the cells were collected from more mature biofilms, namely from 48 and $72 \mathrm{~h}$ biofilms. To assess this, the antimicrobial susceptibility of Brc obtained at 28, 48 and 72 hours to peak serum concentrations of vancomycin, tetracycline and rifampicin was determined. Interestingly, no significant differences in the tolerance to vancomycin, tetracycline or rifampicin were found between the different Brc populations, obtained $4 \mathrm{~h}(28 \mathrm{H}$ biofilms $)$ or $24 \mathrm{~h}(48 \mathrm{H} / 72 \mathrm{H}$ biofilms) after medium replacement (Supplementary Data S2). This data is indirect evidence suggesting that the overall phenomenon of Brc is not affected 242 by the maturity of the biofilm.

\section{Discussion}

It has been pointed out that during biofilm disassembly phase, cells are released from the biofilm 
247 to the surrounding environment, spreading the infection and increasing the risk of systemic 248 diseases, as bacteraemia (Boles and Horswill, 2011; Cervera et al., 2009). Recently, we 249 demonstrated the feasibility of using a fed-batch system to obtain Brc from high biofilm-forming 250 S. epidermidis strains (França et al., 2016a), and showed that Brc had enhanced tolerance to 251 antibiotics (Gaio and Cerca, 2019) and also induced a more inflammatory response in the host 252 (França et al., 2016b). An important limitation of the previous studies was the fact that we only 253 tested $\mathrm{ica}^{+}$S. epidermidis isolates, with considerable abilities to form thick and multi-layered 254 biofilms (Christensen et al., 1985; Mack et al., 1994, 1992). As inter- and intra-species variability 255 has been observed regarding Staphylococcal spp. biofilm formation (Handke et al., 2004; Oliveira 256 et al., 2015; Tremblay et al., 2013), it was important to determine if the previous findings were 257 reproducible when using strains with lower ability to form biofilms. Since it is well known that 258 strains without a functional ica operon form biofilms with lower biomass (Handke et al., 2004), 259 we compared $3 \mathrm{ica}^{+}$and $3 \mathrm{ica}^{-}$isolates.

260 Not surprisingly, significant differences were found between $\mathrm{ica}^{+}$and $\mathrm{ica}^{-}$isolates, regarding the 261 effect of shear forces on the biofilm biomass reduction. A higher proportion of cells was found to 262 be detached from weaker biofilms, as well as the decrease on total biofilm biomass was 263 significantly more pronounced on $i \mathrm{ca}^{-}$isolates, while a similar number of cells was being removed 264 from the second to the last washing step, suggesting an almost inversely proportional ability to 265 physically detach cells from the biofilms as related to the biofilm cohesiveness (Mack et al., 1996). 266 The opposite was found for stronger biofilms, as it seems that a higher number of cells was 267 recovered from initial washes (W1 and W2), but remarkably lower amounts of cells were detached 268 in the last stages of washing, presumably because deeper layers of the biofilm are more cohesive 269 and resistant to shear forces.

270 We also assessed if the enhanced antimicrobial tolerance described before (França et al., 2016a) 271 was dependent on biofilm maturation stage. By obtaining Brc from $\sim 1,2$ and 3 day-old biofilms, 272 we were able to determine that the effect observed in early-stage biofilms also occurred in older 273 biofilms.

274 As noted before, a key limitation of using a fed-batch model to originate Brc is the difficulty to 275 differentiate between physically detached cells, resulting from the washing procedures, from 276 actively dispersed cells (Boles and Horswill, 2011; França et al., 2016a; Kaplan, 2010). As shown 277 with the multiple washing steps experiment, our data confirm that shear forces exerted during 
278 washing and medium replacement trigger the detachment of cells, independently of the ability of 279 the isolates to produce thicker or thinner biofilms or the number of washes involved. However, 280 active dispersion could only be determined in the $i c a^{+}$strains tested. Conversely, for the strains 281 without a functional ica operon, the quantity of cells on the biofilm bulk fluid incubated in the 282 presence or absence of the biofilm was generally the same. This phenomenon in ica- isolates may 283 be a consequence of the large proportion of cells removed upon washing their weak biofilms, 284 which led to a higher proportion of cells in the supernatant immediately upon the addition of fresh 285 media and, consequently, to a lower availability of cells in the biofilm to be continuously released. 286 On the other hand, stronger biofilms were less affected by the washing steps used to remove non287 adherent cells, leading to a lower proportion of cells detached from shear forces, compared to the 288 originating biofilm, and, consequently, to a higher concentration of cells actively released from 289 the biofilm to the supernatant.

290

\section{Conclusions}

292 The results obtained herein demonstrated that a fed-batch system is only reliable in obtaining Brc 293 from S. epidermidis biofilms for some isolates, especially from those who can form thick and 294 strong biofilms. While all ica ${ }^{+}$isolates used herein were found to be high biofilm producing 295 strains, it should be noted that some $i \mathrm{ca}^{+}$isolates lack a functional intact operon (Cafiso et al., 2004; Cue et al., 2012), and the mere presence of the gene might not be related to its expression (Freitas et al., 2017; Lerch et al., 2019). As such, to assess the feasibility of this method in more strains, it is important not only to determine the presence of ica but to assess if the operon is functional, as mutations in major biofilm regulators may influence the dynamics of Brc production (Cue et al., 2012).

301

302

303

\section{References}

Albano, M., Karau, M.J., Greenwood-Quaintance, K.E., Osmon, D.R., Oravec, C.P., Berry, D.J., 305 Abdel, M.P., Patel, R., 2019. In vitro activity of rifampin, rifabutin, rifapentine, and rifaximin against planktonic and biofilm states of staphylococci isolated from periprosthetic joint infection. Antimicrob. Agents Chemother. doi:10.1128/AAC.00959-19

Azeredo, J., Azevedo, N.F., Briandet, R., Cerca, N., Coenye, T., Costa, A.R., Desvaux, M., Di 
309

310

311

312

313

314

315

316

317

318

319

320

321

322

323

324

325

326

327

328

329

330

331

332

333

334

335

336

337

338

339

Bonaventura, G., Hébraud, M., Jaglic, Z., Kačániová, M., Knøchel, S., Lourenço, A., Mergulhão, F., Meyer, R.L., Nychas, G., Simões, M., Tresse, O., Sternberg, C., 2017. Critical review on biofilm methods. Crit. Rev. Microbiol. doi:10.1080/1040841X.2016.1208146

Bahamondez-Canas, T.F., Heersema, L.A., Smyth, H.D.C., 2019. Current status of in vitro models and assays for susceptibility testing for wound biofilm infections. Biomedicines. doi:10.3390/biomedicines7020034

Becker, K., Heilmann, C., Peters, G., 2014. Coagulase-negative staphylococci. Clin. Microbiol. Rev. 27, 870-926. doi:10.1128/CMR.00109-13

Boles, B.R., Horswill, A.R., 2011. Staphylococcal biofilm disassembly. Trends Microbiol. 19, 449-55. doi:10.1016/j.tim.2011.06.004

Cafiso, V., Bertuccio, T., Santagati, M., Campanile, F., Amicosante, G., Perilli, M.G., Selan, L., Artini, M., Nicoletti, G., Stefani, S., 2004. Presence of the ica operon in clinical isolates of Staphylococcus epidermidis and its role in biofilm production. Clin. Microbiol. Infect. doi:10.1111/j.1469-0691.2004.01024.x

Cerca, N., Gomes, F., Bento, J.C., França, A., Rolo, J., Miragaia, M., Teixeira, P., Oliveira, R., 2013. Farnesol induces cell detachment from established S. epidermidis biofilms. J. Antibiot. (Tokyo). 66, 255-258. doi:10.1038/ja.2013.11

Cerca, N., Jefferson, K.K., Oliveira, R., Pier, G.B., Azeredo, J., 2006. Comparative antibodymediated phagocytosis of Staphylococcus epidermidis cells grown in a biofilm or in the planktonic state. Infect. Immun. 74, 4849-4855. doi:10.1128/IAI.00230-06

Cerca, N, Martins, S., Cerca, F., Jefferson, K.K., Pier, G.B., Oliveira, R., Azeredo, J., $2005 a$. Comparative assessment of antibiotic susceptibility of coagulase-negative staphylococci in biofilm versus planktonic culture as assessed by bacterial enumeration or rapid XTT colorimetry. J. Antimicrob. Chemother. 56, 331-336. doi:10.1093/jac/dki217

Cerca, N, Martins, S., Sillankorva, S., Jefferson, K.K., Pier, G.B., Oliveira, R., Azeredo, J., 2005. Effects of growth in the presence of subinhibitory concentrations of dicloxacillin on Staphylococcus epidermidis and Staphylococcus haemolyticus biofilms. Appl. Environ. Microbiol. 71, 8677-8682. doi:10.1128/AEM.71.12.8677-8682.2005

Cerca, N, Pier, G.B., Vilanova, M., Oliveira, R., Azeredo, J., 2005b. Quantitative analysis of adhesion and biofilm formation on hydrophilic and hydrophobic surfaces of clinical isolates 
340

341

342

343

344

345

346

347

348

349

350

351

352

353

354

355

356

357

358

359

360

361

362

363

364

365

366

367

368

369

370

of Staphylococcus epidermidis. Res. Microbiol. 156, 506-14.

doi:10.1016/j.resmic.2005.01.007

Cervera, C., Almela, M., Martínez-Martínez, J.A., Moreno, A., Miró, J.M., 2009. Risk factors and management of Gram-positive bacteraemia. Int. J. Antimicrob. Agents. doi:10.1016/S0924-8579(09)70562-X

Christensen, G.D., Simpson, W.A., Younger, J.J., Baddour, L.M., Barrett, F.F., Melton, D.M., Beachey, E.H., 1985. Adherence of coagulase-negative staphylococci to plastic tissue culture plates: A quantitative model for the adherence of staphylococci to medical devices. J. Clin. Microbiol. 22, 996-1006.

Cogen, A.L., Nizet, V., Gallo, R.L., 2008. Skin microbiota: A source of disease or defence? Br. J. Dermatol. 158, 442-455. doi:10.1111/j.1365-2133.2008.08437.x

Cue, D., Lei, M.G., Lee, C.Y., 2012. Genetic regulation of the intercellular adhesion locus in staphylococci. Front. Cell. Infect. Microbiol. doi:10.3389/fcimb.2012.00038

Dias, C., Borges, A., Oliveira, D., Martinez-Murcia, A., Saavedra, M.J., Simões, M., 2018. Biofilms and antibiotic susceptibility of multidrug-resistant bacteria from wild animals. PeerJ. doi:10.7717/peerj.4974

Dice, B., Stoodley, P., Buchinsky, F., Metha, N., Ehrlich, G.D., Hu, F.Z., 2009. Biofilm formation by ica-positive and ica-negative strains of Staphylococcus epidermidis in vitro. Biofouling. doi:10.1080/08927010902803297

França, A., Carvalhais, V., Vilanova, M., Pier, G.B., Cerca, N., 2016a. Characterization of an in vitro fed-batch model to obtain cells released from $S$. epidermidis biofilms. AMB Express 6, 23. doi:10.1186/s13568-016-0197-9

França, A., Pérez-Cabezas, B., Correia, A., Pier, G.B., Cerca, N., Vilanova, M., 2016b. Staphylococcus epidermidis biofilm-released cells induce a prompt and more marked in vivo inflammatory-type response than planktonic or biofilm cells. Front. Microbiol. 7, 1-12. doi:10.3389/fmicb.2016.01530

Freitas, AI; Lopes, N; Oliveira, F; Brás, S; França, A; Vasconcelos, C; Vilanova, M; Cerca, N., 2017. Comparative analysis between biofilm formation and gene expression in commensal and clinical Staphylococcus epidermidis. Future Microbiol. doi: 10.2217/fmb-2017-0140

Freitas, A.I., Vasconcelos, C., Vilanova, M., Cerca, N., 2014. Optimization of an automatic counting system for the quantification of Staphylococcus epidermidis cells in biofilms. J. 
371

372

373

374

375

376

377

378

379

380

381

382

383

384

385

386

387

388

389

390

391

392

393

394

395

396

397

398

399

400

401

Basic Microbiol. 54, 750-757. doi:10.1002/jobm.201200603

Gaio, V., Cerca, N., 2019. Cells released from $S$. epidermidis biofilms present increased antibiotic tolerance to multiple antibiotics. PeerJ 2019. doi:10.7717/peerj.6884

Gardiner, M., Vicaretti, M., Sparks, J., Bansal, S., Bush, S., Liu, M., Darling, A., Harry, E., Burke, C.M., 2017. A longitudinal study of the diabetic skin and wound microbiome. PeerJ. doi:10.7717/peerj.3543

Gray, E.D., Verstegen, M., Peters, G., Regelmann, W.E., 1984. Effect of extracellular slime substance from Staphylococcus epidermidis on the human cellular immune response. Lancet. doi:10.1016/S0140-6736(84)90413-6

Handke, L.D., Conlon, K.M., Slater, S.R., Elbaruni, S., Fitzpatrick, F., Humphreys, H., Giles, W.P., Rupp, M.E., Fey, P.D., O’Gara, J.P., 2004. Genetic and phenotypic analysis of biofilm phenotypic variation in multiple Staphylococcus epidermidis isolates. J. Med. Microbiol. 53, 367-374. doi:10.1099/jmm.0.05372-0

Heilmann, C., Schweitzer, O., Gerke, C., Vanittanakom, N., Mack, D., Götz, F., 1996. Molecular basis of intercellular adhesion in the biofilm-g Staphylococcus epidermidis. Mol. Microbiol. doi:10.1111/j.1365-2958.1996.tb02548.x

Isberg, R.R., Barnes, P., 2002. Dancing with the host: Flow-dependent bacterial adhesion. Cell Press 110, 1-4. doi:10.1016/S0092-8674(02)00821-8

Kaplan, J.B., 2010. Biofilm dispersal: mechanisms, clinical implications, and potential therapeutic uses. J. Dent. Res. 89, 205-218. doi:10.1177/0022034509359403

Kleinschmidt, S., Huygens, F., Faoagali, J., Rathnayake, I.U., Hafner, L.M., 2015. Staphylococcus epidermidis as a cause of bacteremia. Future Microbiol. doi: $10.2217 / \mathrm{fmb} .15 .98$

Laverty, G., Gorman, S.P., Gilmore, B.F., 2013. Biomolecular mechanisms of staphylococcal biofilm formation. Future Microbiol. doi:10.2217/fmb.13.7

Lerch, M.F., Schoenfelder, S.M.K., Marincola, G., Wencker, F.D.R., Eckart, M., Förstner, K.U., Sharma, C.M., Thormann, K.M., Kucklick, M., Engelmann, S., Ziebuhr, W., 2019. A noncoding RNA from the intercellular adhesion (ica) locus of Staphylococcus epidermidis controls polysaccharide intercellular adhesion (PIA)-mediated biofilm formation. Mol. Microbiol. doi:10.1111/mmi. 14238

Mack, D., Fischer, W., Krokotsch, A., Leopold, K., Hartmann, R., Egge, H., Laufs, R., 1996. 
402

403

404

405

406

407

408

409

410

411

412

413

414

415

416

417

418

419

420

421

422

423

424

425

426

427

428

429

430

431

432

The intercellular adhesin involved in biofilm accumulation of Staphylococcus epidermidis is a linear $\beta$-1,6-linked glucosaminoglycan: Purification and structural analysis. J. Bacteriol. doi:10.1128/jb.178.1.175-183.1996

Mack, D., Nedelmann, M., Krokotsch, A., Schwarzkopf, A., Heesemann, J., Laufs, R., 1994. Characterization of transposon mutants of biofilm-producing Staphylococcus epidermidis impaired in the accumulative phase of biofilm production: Genetic identification of a hexosamine-containing polysaccharide intercellular adhesin. Infect. Immun. 62, 3244-3253.

Mack, D., Siemssen, N., Laufs, R., 1992. Parallel induction by glucose of adherence and a polysaccharide antigen specific for plastic-adherent Staphylococcus epidermidis: Evidence for functional relation to intercellular adhesion. Infect. Immun. 60, 2048-2057.

Mah, T., 2012. Biofilm-specific antibiotic resistance. Future Microbiol. 1061-1072. doi: $10.2217 / \mathrm{fmb} .12 .76$

Moormeier, D.E., Bayles, K.W., 2014. Examination of Staphylococcus epidermidis biofilms using flow-cell technology. Methods Mol. Biol. doi:10.1007/978-1-62703-736-5_13

National Committee for Clinical Laboratory Standards, 1997. Methods for dilution: antimicrobial susceptibility tests for bacteria that grow aerobically - Fifth Edition: Approved Standard M7-A5. NCCLS, Wayne, PA, USA.

O'Gara, J.P., 2007. ica and beyond: Biofilm mechanisms and regulation in Staphylococcus epidermidis and Staphylococcus aureus. FEMS Microbiol. Lett. doi:10.1111/j.15746968.2007.00688.x

Oliveira, F., Lima, C.A., Bras, S., França, A., Cerca, N., 2015. Evidence for inter- and intraspecies biofilm formation variability among a small group of coagulase-negative staphylococci. FEMS Microbiol. Lett. 362, 1-20. doi:10.1093/femsle/fnv175

Otto, M., 2009. Staphylococcus epidermidis - the'accidental'pathogen. Nat. Rev. Microbiol. 7, 555-567. doi:10.1038/nrmicro2182.Staphylococcus

Otto, M., 2013. Staphylococcal infections : mechanisms of biofilm maturation and detachment as critical determinants of pathogenicity. Ann. Rev. Microbiol. doi:10.1146/annurev-med042711-140023

Periasamy, S., Joo, H., Duong, A.C., Bach, T.L., Tan, V.Y., Chatterjee, S.S., Cheung, G.Y.C., Otto, M., 2012. How Staphylococcus aureus biofilms develop their characteristic structure. Proc. Natl. Acad. Sci. U. S. A. 109, 1281-6. doi:10.1073/pnas.1115006109 
433 Qin, Z., Ou, Y., Yang, L., Zhu, Y., Tolker-Nielsen, T., Molin, S., Qu, D., 2007a. Role of

434 autolysin-mediated DNA release in biofilm formation of Staphylococcus epidermidis.

435 Microbiology. doi:10.1099/mic.0.2007/006031-0

436 Qin, Z., Yang, X., Yang, L., Jiang, J., Ou, Y., Molin, S., Qu, D., 2007b. Formation and

437 properties of in vitro biofilms of ica-negative Staphylococcus epidermidis clinical isolates.

438 J. Med. Microbiol. doi:10.1099/jmm.0.46799-0

439 Rogers, K.L., Fey, P.D., Rupp, M.E., 2009. Coagulase-negative staphylococcal infections. Infect.

440 Dis. Clin. North Am. 23, 73-98. doi:10.1016/j.idc.2008.10.001

441 Schommer, N.N., Christner, M., Hentschke, M., Ruckdeschel, K., Aepfelbacher, M., Rohde, H., 442 2011. Staphylococcus epidermidis uses distinct mechanisms of biofilm formation to

443

444

445

446

447

448

449

450

451

452

453

454

455

456

457

458

459

460

461

462

463 interfere with phagocytosis and activation of mouse macrophage-like cells 774A.1. Infect. Immun. 79, 2267-2276. doi:10.1128/IAI.01142-10

Singh, R., Ray, P., 2014. Quorum sensing-mediated regulation of staphylococcal virulence and antibiotic resistance. Future Microbiol. 9, 669-81. doi:10.2217/fmb.14.31

Sousa, C., França, A., Cerca, N., 2014. Assessing and reducing sources of gene expression variability in Staphylococcus epidermidis biofilms. Biotechniques 57, 295-301. doi:10.2144/000114238

Tormo, M.A., 2005. Bap-dependent biofilm formation by pathogenic species of Staphylococcus: evidence of horizontal gene transfer? Microbiology 151, 2465-2475. doi:10.1099/mic.0.27865-0

Tremblay, Y.D.N., Lamarche, D., Chever, P., Haine, D., Messier, S., Jacques, M., 2013. Characterization of the ability of coagulase-negative staphylococci isolated from the milk of Canadian farms to form biofilms. J. Dairy Sci. 96, 234-246. doi:10.3168/jds.2012-5795

Wang, R., Khan, B.A., Cheung, G.Y.C., Bach, T.H.L., Jameson-Lee, M., Kong, K.F., Queck, S.Y., Otto, M., 2011. Staphylococcus epidermidis surfactant peptides promote biofilm maturation and dissemination of biofilm-associated infection in mice. J. Clin. Invest. 121, 238-248. doi:10.1172/JCI42520

Yao, Y., Sturdevant, D.E., Otto, M., 2005. Genomewide analysis of gene expression in Staphylococcus epidermidis biofilms: insights into the pathophysiology of $S$. epidermidis biofilms and the role of phenol-soluble modulins in formation of biofilms. J. Infect. Dis. 191, 289-298. doi:10.1086/426945 
464 Yawata, Y., Nguyen, J., Stocker, R., Rusconi, R., 2016. Microfluidic studies of biofilm 465 formation in dynamic environments. J. Bacteriol. doi:10.1128/JB.00118-16

466 Ziebuhr, W., Hennig, S., Eckart, M., Kränzler, H., Batzilla, C., Kozitskaya, S., 2006. Nosocomial 467 infections by Staphylococcus epidermidis: how a commensal bacterium turns into a 468 pathogen. Int. J. Antimicrob. Agents. doi:10.1016/j.jjantimicag.2006.05.012

469 


\section{Table $\mathbf{1}$ (on next page)}

Origin of the 11 Staphylococcus epidermidis isolates used in this study. 
1 Table 1. Origin of the 6 Staphylococcus epidermidis isolates used in this study
S. epidermidis
Description
Country of origin
Ica operon
isolate

\begin{tabular}{|c|c|c|c|}
\hline $\begin{array}{c}9142 \text { (Mack et al., } \\
\text { 1992) }\end{array}$ & $\begin{array}{l}\text { Clinical isolate from blood } \\
\text { culture }\end{array}$ & Germany & $\begin{array}{c}\text { Detected } \\
\text { (Cerca et al., } \\
\text { 2013) }\end{array}$ \\
\hline $\begin{array}{l}\text { DEN69 (Cerca et } \\
\text { al., 2013) }\end{array}$ & Unknown & Denmark & $\begin{array}{c}\text { Detected } \\
\text { (Cerca et al., } \\
\text { 2013) }\end{array}$ \\
\hline PT13032 1 & $\begin{array}{l}\text { Clinical isolate from a patient } \\
\text { with chronic renal failure }\end{array}$ & Portugal & Detected ${ }^{1}$ \\
\hline $\begin{array}{l}\text { ICE102 (Cerca et } \\
\text { al., 2013) }\end{array}$ & $\begin{array}{l}\text { Clinical isolate from a patient } \\
\text { with infective endocarditis }\end{array}$ & Iceland & $\begin{array}{c}\text { Undetected } \\
\text { (Cerca et al., } \\
\text { 2013) }\end{array}$ \\
\hline $\begin{array}{l}\text { DEN185 (Cerca } \\
\text { et al., 2013) }\end{array}$ & Unknown & Denmark & $\begin{array}{c}\text { Undetected } \\
\text { (Cerca et al., } \\
\text { 2013) }\end{array}$ \\
\hline $\begin{array}{l}\text { PT12004 (Freitas } \\
\text { et al., 2017) }\end{array}$ & $\begin{array}{l}\text { Clinical isolate from a patient } \\
\text { with chronic renal failure }\end{array}$ & Portugal & $\begin{array}{c}\text { Undetected } \\
\text { (Freitas et al., } \\
\text { 2017) }\end{array}$ \\
\hline
\end{tabular}

$2{ }^{1}$ Unpublished isolate obtained from a previous epidemiological study in Portugal. Isolates were obtained after patient informed consent with the approval of the Ethical Committee of the Hospital Geral de Santo António, Porto, Portugal. Each isolate was first identified at the species level using the commercially available VITEK ${ }^{\circledR}$ two identification system using the gram-positive ID card (BioMérieux, Marcy l'Etoile, France) and molecular identification was confirmed by sequencing of the $r p o B$ gene (Mellmann et al., 2006). 


\section{Table 2 (on next page)}

Characterization of biofilm biomass

Characterization of biofilm biomass (by OD measurements) and the ratios between the biofilm bulk fluid, containing Brc, and the biofilm suspension (Brc/Bio). 
1 Table 2. Characterization of biofilm biomass (by OD measurements) and the ratios between the biofilm 2 bulk fluid, containing Brc, and the biofilm suspension (Bbf/B).

3

\begin{tabular}{c|cccccc}
\multirow{2}{*}{ Classification } & S. epidermidis isolates & \multicolumn{3}{c}{ OD Biofilm } & \multicolumn{3}{c}{ Ratio Bbf/B } \\
\cline { 2 - 7 } & & $\mathbf{2 8 H}$ & $\mathbf{4 8 H}$ & $\mathbf{7 2 H}$ & $\mathbf{2 8 H}$ & $\mathbf{4 8 H}$ \\
\multirow{3}{*}{$i c a^{+}$} & $\mathbf{9 1 4 2}$ & 1.65 & 2.54 & 3.05 & 0.64 & 0.47 \\
& DEN69 & 1.92 & 1.92 & 2.26 & 0.51 & 0.79 \\
& PT13032 & 0.48 & 0.88 & 1.29 & 1.10 & 1.29 \\
$i c a^{-}$ & ICE102 & 0.61 & 0.81 & 0.89 & 2.12 & 3.65 \\
& DEN185 & 0.43 & 0.78 & 0.77 & 2.85 & 3.63 \\
& PT12004 & 0.57 & 0.69 & 0.72 & 1.81 & 2.77
\end{tabular}

4

5 
Figure 1

Scheme illustrating the process of obtaining biofilm released cells using a fed-batch growth system.
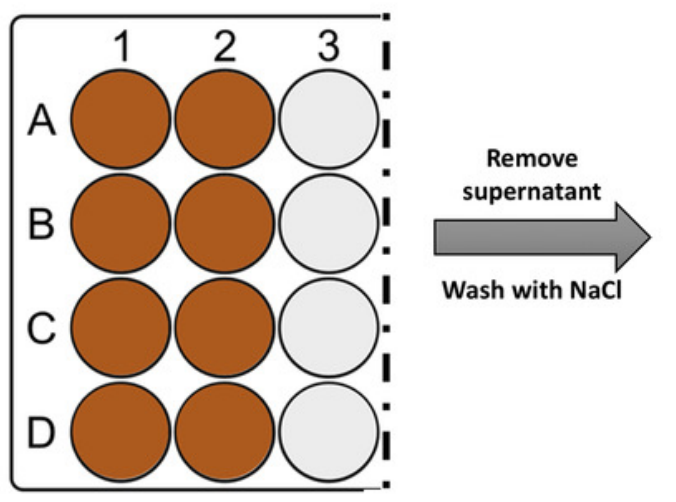

Preformed $24 \mathrm{~h}$ biofilms (BF)

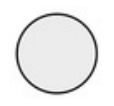

Sterile wells
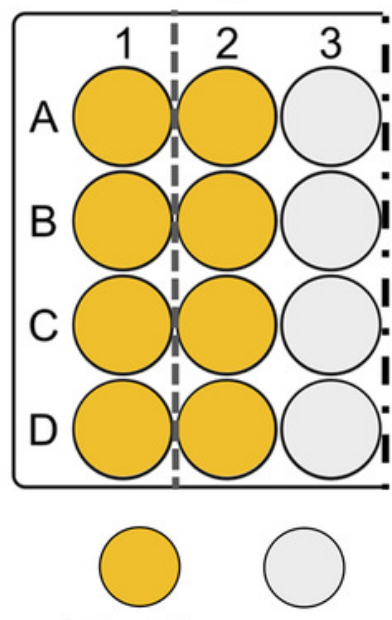

Sterile wells
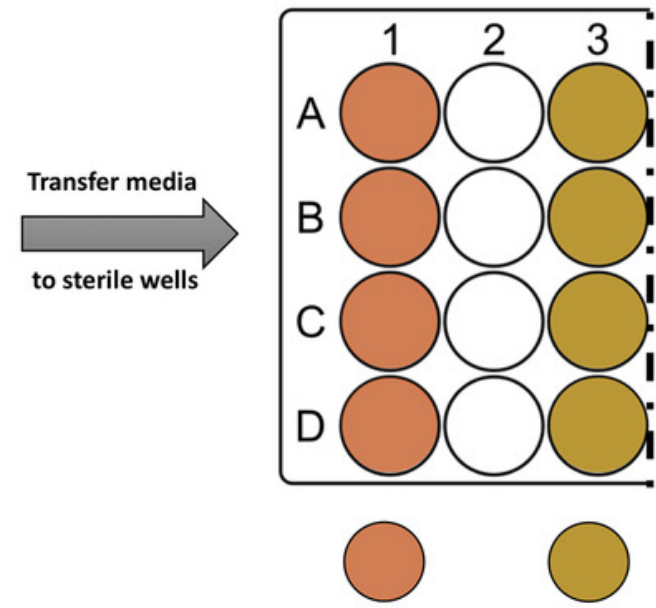

BF-dependent growth

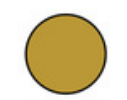

BF-independent growth 


\section{Figure 2}

$\log _{10}$ number of CFU in the biofilm or in the wash liquid after continuous washing steps in (A-C) S. epidermidis ica ${ }^{+}$isolates or (D-F) S. epidermidis ica isolates.

CFU were determined from biofilms after 1 (BF1), 2 (BF2) or 6 washes (BF6) and from the $\mathrm{NaCl}$ solution obtained after each washing step (W1 to W6). The columns represent the mean plus or minus standard error deviation of at least three independent experiments, with duplicates. Statistical differences were analyzed with one-way ANOVA multiple comparisons, with $\alpha$ representing statistically significant differences $(p<0.05)$ between the first condition (BF1 or W1) and all remaining conditions, while $\beta$ represents significant differences $(p<0.05)$ between each consecutive washing step. 
A

9142

D
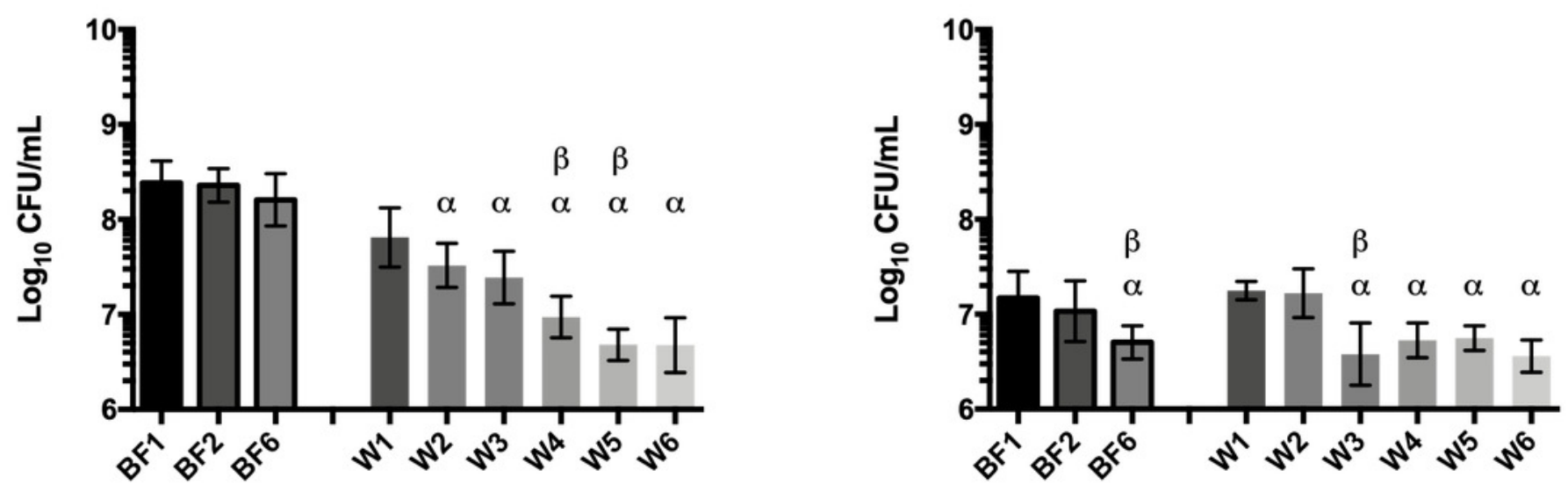

B

DEN69

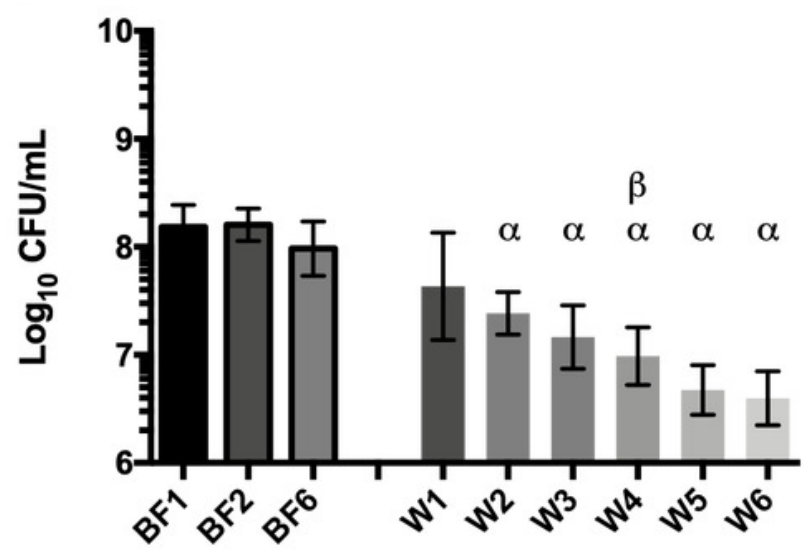

E

DEN185
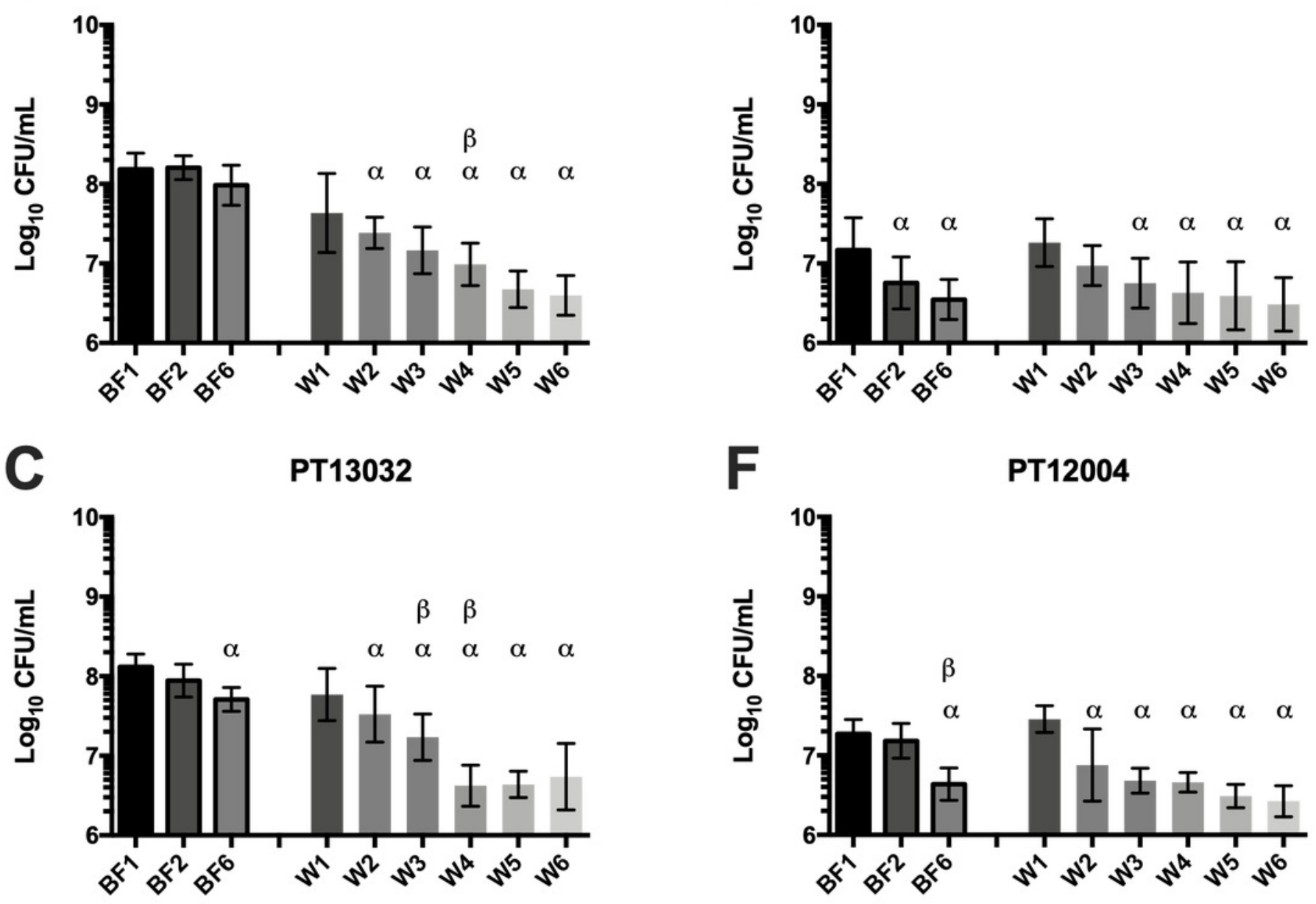

F

PT12004

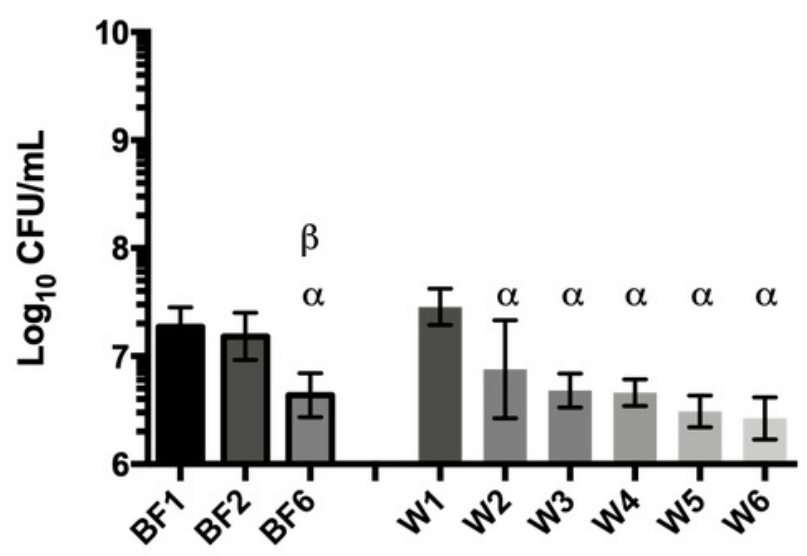




\section{Figure 3}

Growth kinetics ( $\log _{10} \mathrm{CFU} / \mathrm{mL}$ ) of $\mathrm{Brc}$ in the presence or absence of the originating biofilms, under agitation (120 rpm) in (A-C) S. epidermidis ica ${ }^{+}$isolates or (D-F) S. epidermidis ica" isolates.

The number of CFU was determined at 0,60 and 120 minutes after media change in the presence (BF-dependent) or absence (BF-independent) of the originating biofilm. The columns represent the mean plus or minus standard error deviation of at least three independent experiments. Statistical differences were analyzed with multiple T-tests, with $\mathrm{Y}$ $(p<0.01)$ representing statistically significant differences between the number of cells recovered at each time point between growth in both conditions (BF- dependent and independent). 


\section{$\rightarrow$ BF-dependent}

A

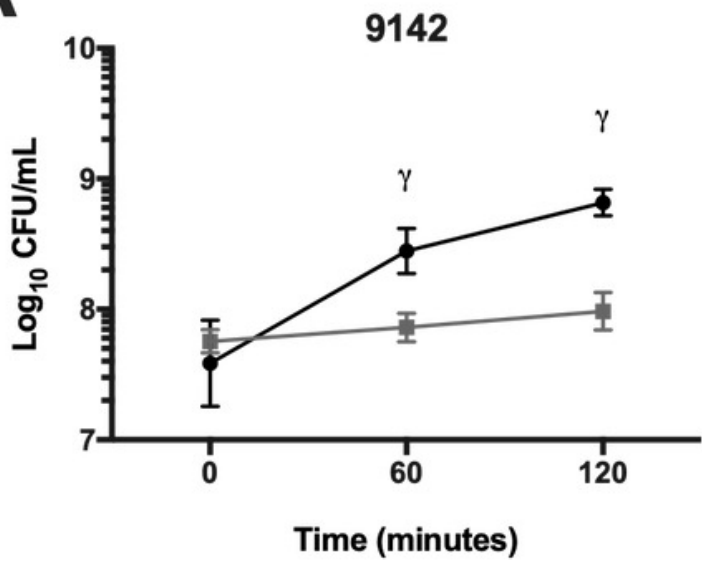

B
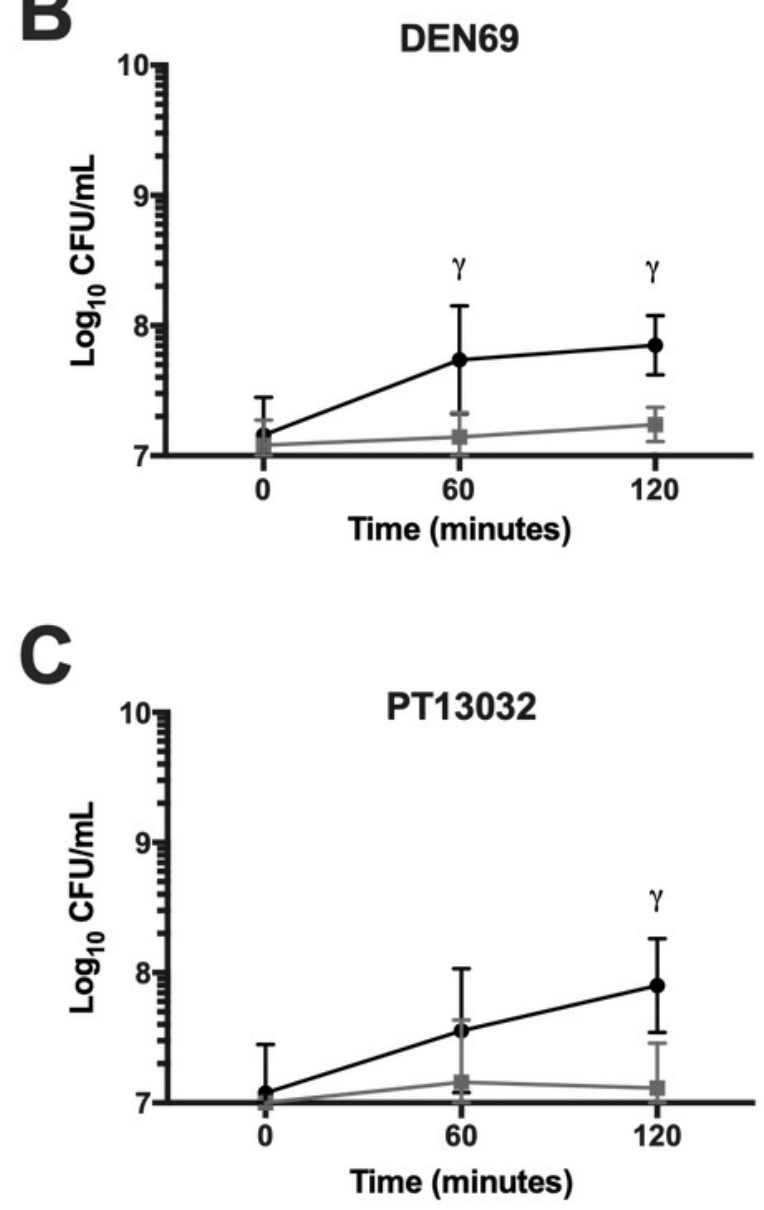

$\rightarrow$ BF-independent
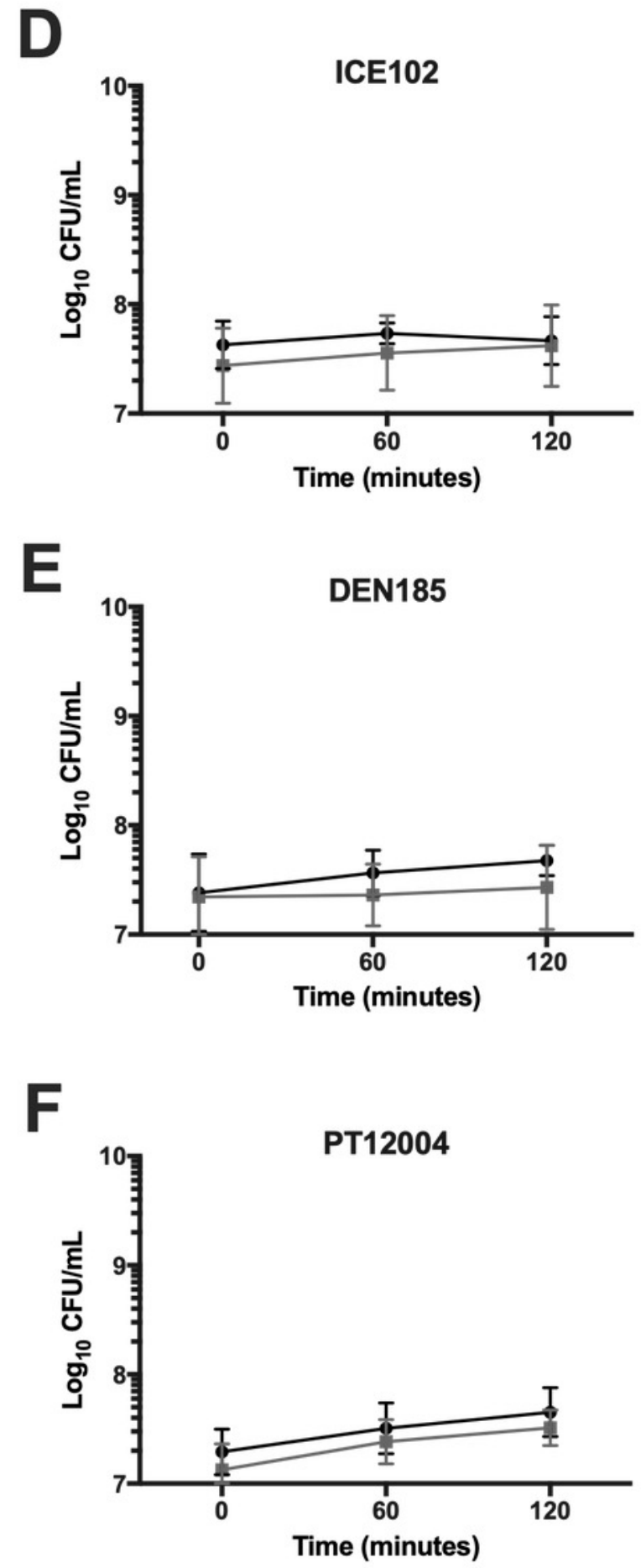